\title{
Opening Address: President of IMU
}

\author{
Ingrid Daubechies
}

It is a great pleasure for me to have the opportunity to address you, during this opening ceremony for the 12th International Congress on Mathematical Education, in my capacity as President of the International Mathematical Union, or IMU.

Officially, that is, with respect to the International Council for Science (or ICSU), which itself reports to UNESCO, IMU is the umbrella organization concerned with matters of global interest to mathematicians worldwide. The International Commission on Mathematical Instruction (or ICMI for brevity), which organizes the quadrennial ICME meetings, is the most important sub-organization of the IMU. In fact, and as ICMI President Bill Barton likes to remind me goodhumoredly, ICMI is older than the IMU itself, since it was created in 1908-IMU was created only in 1920, and even then it was an earlier incarnation that stopped functioning in the 1930s; in its present version, it was reborn in 1951.

An extremely important charge for the IMU is to organize the prestigious quadrennial International Congresses of Mathematicians, or ICMs, the first one of which dates back to 1893; it is probably no exaggeration to state that the IMU was first started to ensure a regular and orderly organization of the ICMs. This is similar to the role ICMI plays with respect to the ICME congresses, which are all held under ICMI's auspices and principles. Once the ICME series hit its quadrennial rhythm, it became customary to hold the ICMs and ICMEs in interleaved evennumbered years, keeping stride nicely with the World Cup in Soccer/Football and the Olympic Games, which one could view as a "warm-up" for our more serious pursuits. The next ICM will thus take place in 2014, coincidentally in this very same city, in this very same Conference Center.

Over the years, IMU has come to stand for much more than just the umbrella organization ensuring continuity for the ICMs. In the past few decades, IMU has become more concerned with assisting developing countries build up their own

I. Daubechies $(\square)$

Duke University, Durham, USA

e-mail: ingrid@math.duke.edu

(C) The Author(s) 2015

S.J. Cho (ed.), The Proceedings of the 12th International Congress

on Mathematical Education, DOI 10.1007/978-3-319-12688-3_1 
strong mathematics communities. IMU is also solidly and seriously invested in helping develop and sustain excellent mathematics education everywhere, and at all levels - although the work of my colleagues on the Executive Committee of the IMU, as well as my own, is anchored in mathematics research, we all realize fully the importance of teaching mathematical insights, understanding and skills in the best possible way, and we are committed to help ICMI as much as we can in pursuing this goal. These are not empty words-we are acting on our beliefs! The following are just two examples. In setting up the new stable central Secretariat for the IMU, it was viewed as an essential and core part of its charge that it provides a stable administrative support and archival role for ICMI as well. On a different note, IMU is also actively helping ICMI in finding and providing funding for the very important CANP workshops, which build networking for mathematics educators in less developed regions in the world.

I am personally thrilled by this tighter connection between mathematical researchers and experts on, or researchers in, mathematical education. Whether we decide to contribute to mathematical research, or whether we decide to invest our creative energy in mathematics education-you and I, ICME or ICM participants, we are ALL mathematicians, united in our love for mathematics. It was a proud moment in my life when my son announced his decision to become a high school teacher in mathematics; he now teaches in one of the inner city schools in Chicago, and works hard to ignite and keep alive an interest in mathematics among his students, bringing to this the energy and drive that he could easily have taken to graduate school. I respect and value the commitment and engagement of teachers like him, and I encourage all professional research mathematicians to do likewise.

Dear ICME-12 Participants, fellow mathematicians, focused on bringing the best possible mathematics education to future generations, I salute you!

And I wish you a wonderful Congress.

Open Access This chapter is distributed under the terms of the Creative Commons Attribution Noncommercial License, which permits any noncommercial use, distribution, and reproduction in any medium, provided the original author(s) and source are credited. 